\title{
Low Malaria Prevalence in HIV-Positive Patients in Bamenda, Cameroon
}

\author{
Longdoh A. Njunda ${ }^{1}$, Henri-Lucien F. Kamga ${ }^{1}$, Dickson S. Nsagha ${ }^{2}$, Jules-Clement N Assob ${ }^{3}$, \\ Tebit E. Kwenti, ${ }^{1, *}$ \\ ${ }^{1}$ Department of Medical Laboratory Sciences, Faculty of Health Sciences, University of Buea, Buea, Box 63, Cameroon
${ }^{2}$ Department of Public Health and Hygiene, Faculty of Health Sciences, University of Buea, Buea, Box 63, Cameroon
${ }^{3}$ Department of Biomedical Sciences, Faculty of Health Sciences, University of Buea, Buea, Box 63, Cameroon
}

Abstract Data on the prevalence of HIV and malaria coinfection in Cameroon is scanty. The objective of this study was to determine the prevalence of the coinfection in Bamenda which is the major urban city of the North West region of Cameroon, as well as to determine the risk factors that predispose HIV patients in Bamenda to infection with malaria. Subjects were randomly selected as they come for treatment in the HIV treatment center of Bamenda Regional Hospital and screened for malaria parasite. Of the $312 \mathrm{HIV}$ patients who enrolled into the study, 231 (74\%) were females and 81 (26\%) were males. The median age of the participants was 38years. $80 \%$ of the HIV patients were on treatment for HIV and other opportunistic infections. 90 (28.8\%) admit using mosquito net meanwhile $222(71.2 \%)$ did not. Upon examining the blood sample from these patients, $7(2 \cdot 24 \%)$ were coinfected with malaria. Among these 7 patients, only 2 were using mosquito net, and a majority of them were females (6). We therefore came to the conclusion that the prevalence rate of HIV and malaria coinfection was low and not using mosquito net is not a major risk factor $(\mathrm{OR}=1 \cdot 01, P=1 \cdot 0)$ for coinfection with malaria in HIV patients in Bamenda.

Keywords HIV, Malaria, Prevalence, Coinfection

\section{Introduction}

Sub-Saharan Africa is home to some of the world's most deadly diseases. HIV/AIDS and malaria are both diseases of the poor and contribute to the poverty of Sub-Saharan Africa nations by taking a heavy toll on young people who contribute greatly to the workforce of the local economy[1]. In 2007, HIV/AIDS and malaria accounted for over 3 million deaths in Sub-Saharan Africa[2,3].

Earlier studies attempted with difficulties to establish an association between HIV and malaria[4,5], however recent studies suggest that repeated infection with malaria result in a more rapid decline in CD4+ T cells overtime meanwhile, malaria coinfection with HIV results in more episodes of symptomatic malaria[6] and more episodes of severe or complicated malaria including death in both children and adults[7-11].

In Cameroon, malaria was responsible for $48 \cdot 5 \%$ of all-cause admission in hospitals and $28.9 \%$ of all deaths in 2009[12]. The major Plasmodium species is falciparium which is transmitted through the bite of an infected female Anopheles mosquito of a good number of species (gambiae,

* Corresponding author:

kwentitebit@yahoo.com (Tebit E. Kwenti)

Published online at http://journal.sapub.org/microbiology

Copyright (C) 2012 Scientific \& Academic Publishing. All Rights Reserved arabiensis, funestus and moucheti)[12]. Mosquito bites are common all year round with certain peak period which therefore exposes a greater population at risk of malaria infection[12]. One of the major predisposing factors to severe or complicated malaria infection is HIV. A study in Douala, Cameroon gave a very high prevalence $(29 \cdot 4 \%)$ of HIV and malaria coinfection[11]. However data in other regions of the country are not readily available. The objective of this study was therefore to determine the prevalence of coinfection with HIV and malaria in Bamenda, the major urban center of the North West region of Cameroon, which will add to the available baseline data of both infections in the country.

\section{Materials and Methods}

\subsection{Study Area}

The study was carried out in Bamenda using the HIV/AIDS treatment center of the Bamenda Regional Hospital. Bamenda is the capital of the North West Region of Cameroon (a country situated on the west wing of Central Africa). The region has the major characteristic of a savanna, with two seasons; the dry season which is very dry and dusty spanning from October to April and the wet and cold rainy season which spans from April to October. Bamenda was chosen because it is the region's major urban center, and the 
North West region of Cameroon has a relatively higher prevalence of HIV $(6.9 \%)$ than any other region in the country[13].

\subsection{Study Population}

This study which was approved by the Cameroon ministry of public health ethical committee saw the participation of 312 HIV-positive patients, $81(26 \%)$ males and 231 (74\%) females. The median age was 38years (Q1 and Q3 were 31 years and 47years respectively). The participants were administered a standard questionnaire on their usage of mosquito nets and treatment regimen for HIV. After obtaining their informed consent, capillary blood was collected onto clean glass sides by finger stick in August 2011. The blood was then smeared and air dried prior to staining with Giemsa. Staining was done for 30 minutes with a 1 in 20 dilution of Giemsa.

\subsection{Determination of Malaria Parasitaemia}

Malaria parasitaemia was determined in Giemsa-stained smears using light microscopy. The parasites in each thick film were counted until 200WBC were observed. The number of parasites that were observed was divided by 200 and multiplied by $8000 / \mu 1$ to give parasite/ $\mu 1$ of blood[14].

\subsection{Statistical Analysis}

Statistical analyses were performed with the MINITAB 15 English. Differences between proportions were determined using the Chi-square Goodness-of-fit test and Fisher's exact test. $P$ values $<0.05$ were consider to be statistically sensitive and represents $95 \%$ of the population.

\section{Results}

Among the 312 participants, $249(80 \cdot 0 \%)$ were infected with HIV-1, $22(7 \cdot 0 \%)$ with HIV-2 and $41(13 \cdot 0 \%)$ with HIV-1\&2 (Table 1). 249(80\%) of 312 patients were on treatment for HIV and other opportunistic infections. 7 of the 312 slides examined were positive for malaria parasite giving a prevalence rate of $2.24 \%$ (95\% CI: $0 \cdot 6$ - 3.88). Among those positive were 6 females and 1 male. The mean parasitaemia was 1103 parasites $/ \mu 1$.

4 of the 7 samples that were found to be positive for malaria parasite were from patients infected with HIV-1 (Table 1). The rate was found to be higher in HIV-2 patients $(9 \cdot 1 \%)$. However the difference in the rate of malaria infection with respect to HIV type was not found to be significant statistically $\left(\chi^{2}=4 \cdot 66, \mathrm{DF}=2, P=0 \cdot 05\right)$.

Table 1. Distribution of malaria parasitaemia among the different HIV types

\begin{tabular}{lcc}
\hline HIV type & \% in all HIV patients & № infected with mp \\
HIV-1 & $249(80 \%)$ & $4(1 \cdot 6 \%)$ \\
HIV-2 & $22(7 \%)$ & $2(9 \cdot 1 \%)$ \\
HIV-1\&2 & $41(13 \%)$ & $1(2 \cdot 4 \%)$ \\
Total & 312 & 7 \\
\hline
\end{tabular}

Malaria and HIV coinfection was seen more in females $(2 \cdot 6 \%)$ than in males $(1 \cdot 24 \%)$ (Table 2$)$. The difference in the rate of malaria infection in females and males was not found to be significant statistically $\left(\chi^{2}=0 \cdot 5, \mathrm{DF}=1, P>0 \cdot 2\right)$.

Table 2. The distribution of malaria infection according to sex, and age in HIV patients in Bamenda

\begin{tabular}{clc}
\hline AGE RANGE & $\mathbf{n}$ & № patients positive for malaria \\
$\mathbf{1 8}-\mathbf{3 0}$ & 71 & $1(1 \cdot 41 \%)$ \\
$\mathbf{3 1}-\mathbf{4 0}$ & 117 & $3(2 \cdot 56 \%)$ \\
$\mathbf{4 1}-\mathbf{5 0}$ & 76 & $0(0 \cdot 00 \%)$ \\
$\mathbf{5 1}-\mathbf{6 0}$ & 37 & $1(2 \cdot 70 \%)$ \\
$\mathbf{6 1}-\mathbf{7 0}$ & 7 & $1(14.29 \%)$ \\
$>\mathbf{7 0}$ & 4 & $1(25 \cdot 00 \%)$ \\
$\mathbf{N}$ & 312 & $7(2 \cdot 24 \%)$ \\
Females & 231 & $6(2 \cdot 60 \%)$ \\
Male & 81 & $1(1 \cdot 24 \%)$ \\
\hline
\end{tabular}

$90(28 \cdot 8 \%)$ of the participants were found to be sleeping under a mosquito net meanwhile $222(71 \cdot 2 \%)$ did not sleep under a mosquito net. Malaria infection was therefore common in individuals who did not sleep under a mosquito net as oppose to individuals who sleep under a mosquito net, as well as in females than in males (Table 3).

Table 3. Risk factors for malaria infection in HIV-positive patients

\begin{tabular}{llll}
\hline Risk factors & $\begin{array}{l}\text { № of } \\
\text { participants }\end{array}$ & Proportion & OR, 95\% CI \\
\hline Use mosquito net & $90(28 \cdot 8 \%)$ & $2(2 \cdot 22 \%)$ & $1 \cdot 00$ \\
$\begin{array}{l}\text { Do not use } \\
\text { mosquito net }\end{array}$ & $222(71 \cdot 2 \%)$ & $5(2 \cdot 25 \%)$ & $1 \cdot 01(1 \cdot 00-1 \cdot 02), P=1 \cdot 0$ \\
Males & $81(26 \%)$ & $1(1 \cdot 24 \%)$ & $1 \cdot 00$ \\
Females & $231(74 \%)$ & $6(2 \cdot 60 \%)$ & $2 \cdot 13(1 \cdot 96-2 \cdot 30), P=0.7$ \\
\hline
\end{tabular}

\section{Discussion}

Recent studies have shed the light on the link between HIV and malaria and the potential public health implications of coinfection. Sub-Saharan Africa represents a region with overlapping distribution of HIV and malaria, with approximately 22.5 million HIV patients[13] and a majority of malaria cases with resultant death[15], more than any other region in the world. In Cameroon, malaria was responsible for $28.9 \%$ of all-cause death in 2009[12]. One of the major predisposing factors for severe malaria infection is coinfection with HIV[9]. However, data on the coinfection in $\mathrm{Ca}$ meroon is still very scanty. This study designed to determine the prevalence of the coinfection in Bamenda, the major urban city of the North West region of Cameroon, gave a prevalence rate of $2.24 \%$ (95\% CI: $2.06-2.43)$. The rate recorded here is very low when compared to the prevalence rate of $29.4 \%$ recorded in Douala[11]. The mean parasitaemia that was observed in this study was 1103 parasites $/ \mu 1$, which is equally low. In addition to the fact that malaria in HIV is more severe[7-11], and infected patients will quickly go down with the disease and seek medical attention faster, there are other factors that may have contributed to this low prevalence rate, notably the age of the participants, the climate of Bamenda, treatment for HIV and the usage of 
mosquito nets.

From this study, it was observed that the mean age of the participants was 38 years. Malaria has been shown to affect mostly children below 5 years[16] meanwhile HIV is more common in the sexually active proportion of the population.

The lifecycle of the mosquito and the transmission dynamics of the diseases they transmits have been shown to be strongly influenced by climatic variables[17]. The development of the malaria parasite in the mosquito and rate of biting decreases at low temperature[18]. The period (August) during which this study was done corresponds to the cold, wet season with peaked rainfall.

It was also observed that $80 \%$ of the participants were already on treatment for HIV and other opportunistic infections. One of the most common components of the treatment was cotrimoxazole (Bactrim). Trimothoprim-sulfame-thoxazole which is the active ingredient of Bactrim is also effective therapeutically against malaria[19,20]. And will therefore protect these patients against infection with malaria.

And lastly, HIV patients in Bamenda have been sensitized on the usage of mosquito nets to prevent infection with malaria. In the study $90(28 \cdot 8 \%)$ of the 312 patients admitted that they are using mosquito nets. This has an effect on the overall outcome of the prevalence rate of malaria in HIV patients in Bamenda.

From the 7 patients from whom malaria parasite was diagnosed, 4 (57\%) were HIV-1 patients. Quite understandably, the majority of patients enrolled on the study were infected with HIV-1 (80\%). Statistics show that there is no difference in the rate in which malaria infect these patients irrespective of the HIV type $\left(\chi^{2}=4.66, \mathrm{DF}=2, \rho>0.05\right)$.

In a bid to assess the risk factors for infection with malaria in HIV patients, it was observed that not using mosquito net was not a major risk factor $(\mathrm{OR}=1 \cdot 01, \mathrm{P}=1 \cdot 0)$ in $\mathrm{HIV}$ patients in Bamenda. Even though it may seem as if the female sex is a risk factor $(\mathrm{OR}=2 \cdot 13)$, this was not found to be significant statistically $(\mathrm{P}=0 \cdot 7)$, owing to the fact that the majority of the participants were females, 231 (74\%) of 312.

\section{Conclusions}

Our study revealed that the prevalence rate of HIV and malaria coinfection in Bamenda is low. The low prevalence can be attributed to the climate of Bamenda, treatment with cotrimoxazole (Bactrim) and the fact that these patients have been sensitized on the usage of mosquito net. Not using mosquito net is therefore not a major risk factor for infection with malaria in HIV patients in Bamenda.

\section{ACKNOWLEDGEMENTS}

We are very grateful to the staffs of the department of Medical laboratory Sciences of the University of Buea for seeing into it that this work is a success.

\section{REFERENCES}

[1] Hochman, S. and Kim, K., 2009, The impact of HIV and malaria coinfection: what is known and suggested venues for further study., Interdisciplinary Perspectives on Infectious Diseases, 617954

[2] UNAIDS, 2007, AIDS epidemic update. UNAIDS and WHO, Geneva, Switzerland

[3] WHO, 2008, World Malaria Report 2008. WHO Press, Geneva, Switzerland

[4] Kalyesubula, I., Musoke-Mudido, P., Marum, L., Bagenda, D., Aceng, E., Ndugwa, C., and Olness, K., 1997, Effects of malaria infection in human immunodeficiency virus type 1infected Ugandan children., Pediatric Infectious Disease Journal, 16(9), 876-881

[5] Chandramohan, D., and Greenwood, B.M., 1998, Is there an interaction between human immunodeficiency virus and Plasmodium falciparum? International Journal of Epidemiology, 27(2), 296-301

[6] Kamya, M.R., Gasasira, A.F., Yeka, A., Bakyaita, N., Nsobya, S.L., Francis, D., Rosenthal, P.J., Dorsey, G., and Havlir, D., 2006, Effect of HIV-1 infection on antimalarial treatment outcomes in Uganda: a population-based study., Journal of Infectious Diseases, 193(1), 9-15

[7] Grimwade, K., French, N., Mbatha, D.D., Zungu, D.D., Dedicoat, M., and Gilks, C.F., 2003, Childhood malaria in a region of unstable transmission and high human immunodeficiency virus prevalence., Pediatric Infectious Disease Journal, 22(12), 1057-1063

[8] Grimwade, K., French, N., Mbatha, D.D., Zungu, D.D., Dedicoat, M., and Gilks, C.F., 2004, HIV infection as a cofactor for severe falciparum malaria in adults living in a region of unstable malaria transmission in South Africa., AIDS, 18(3), $547-554$

[9] Cohen, C., Karstaedt, A., Frean, J., Thomas, J., Govender, N., Prentice, E., Dini, L., Galpin, J., and Crewe-Brown, H., 2005, Increased prevalence of severe malaria in HIV-infected adults in South Africa., Clinical Infectious Diseases, 41(11), $1631-1637$

[10] Otieno, R.O., Ouma, C., Ong'echa, J.M., Keller, C.C., Were, T., Waindi, E.N., Michaels, M.G., Day, R.D., Vulule, J.M., and Perkins, D.J., 2006, Increased severe anemia in HIV-1-exposed and HIV-1-positive infants and children during acute malaria., AIDS, 20(2), 275-280

[11] Nkuo-Akenji, T., Tevoufouet, E.M., Nzang, F., Ngufor, N., and Fon, E., 2008, High prevalence of HIV and malaria co-infection in urban Douala, Cameroon., African Journal of AIDS Research, 7(2), 229-235

[12] WHO, 2010, Cameroon: Epidemiological Profile. World Malaria Report. WHO, Geneva, Switzerland

[13] UNAIDS, 2010, A global view of HIV infection. Cameroon

[14] Cheesbrough, M., 2000, District laboratory practice in tropical countries Part 2. Cambridge Low-price Edition, Cambridge University Press, London, p. 253 - 328

[15] WHO, 2009, Malaria Factsheet: Cameroon

[16] Greenwood, B.M., Bojang, K., Whitty, C.J., and and Targett, 
G.A., 2005, Malaria., Lancet, 365 (9469), 1487-98

[17] Cook, G., ed. 1996, Manson's Tropical Diseases. London:W.B. Saunders Co

[18] Reiter, P.,1998, Global warming and vector-borne disease in temperate regions and at high altitude., Lancet, 351,839-840

[19] Wiktor, S.Z., Sassan-Morokro, M., Grant, A.D., Abouya, L., Karon, J.M., Maurice, C., Djomand, G., Ackah, A., Domoua, K., Kadio, A., Yapi, A., Combe, P., Tossou, O., Roels, T.H., Lackritz, E.M., Coulibaly, D., De Cock, K.M., Coulibaly, I.M., and Greenberg, A.E., 1999, Efficacy of trimetho- prim-sulphamethoxazole prophylaxis to decrease morbidity and mortality in HIV-1-infected patients with tuberculosis in Abidjan, Côte d'Ivoire: a randomised controlled trial., Lancet, 353,1469

[20] Hamel, M.J., Greene, C., Chiller, T., Ouma, P., Polyak, C., Otieno, K., Williamson, J., Shi, Y.P., Feikin, D.R., Marston, B., Brooks, J.T., Poe, A., Zhou, Z., Ochieng, B., Mintz, E., and Slutsker, L., 2008, Does cotrimoxazole prophylaxis for the prevention of HIV-associated opportunistic infections select for resistant pathogens in Kenyan adults? American Journal of Tropical Medicine and Hygiene, 79, 320 